\title{
PERFORMANCE OF A FILL DAM BASED ON THE PERFORMANCE-BASED DESIGN CONCEPT AND STUDY OF A SEISMIC RETROFITTING METHOD
}

\author{
Shigeru TANi ${ }^{\text {i) }}$, Shoichi TsukUnii) and TADAhiko Shiomi ${ }^{\text {iii) }}$
}

\begin{abstract}
Fill dams have long been designed by conventional specification based design methods which stipulate details concerning dam body materials, structural calculation methods, and construction methods. There are irrational aspects to applying the specification based design method to a case subjected to large earthquake such as the 1995 Hyogo-ken Nanbu Earthquake, a type that rarely occurs. Thus, since the Hyogo-ken Nanbu Earthquake, the concept of performance-based design that treats performance of a structure as the only requirement has been incorporated, and conventional specification-based design is now being replaced by performance-based design based on required performance as the design method for structures. When an earthquake strikes a fill dam, water in the dam must not overflow the dam body causing a severe disaster in the area downstream from the dam. It is, therefore, necessary that settlement at a dam crest during an earthquake does not exceed a critical value, requiring that it be designed by an analysis method capable of accurately predicting the quantity of settlement produced. This report describes a design study of a fill dam, which requires a high level of seismic performance because of its location conditions and functions. Performed by applying the concept of ISO23469 to an existing fill dam, the study focused on (1) setting performance criteria, (2) evaluating safety of a fill dam during an earthquake, and (3) reinforcement method that satisfies the performance criteria and evaluation of its safety.
\end{abstract}

Key words: earthquake resistant, fill dam, ISO23469, performance-based design (IGC: E1/E2)

\section{INTRODUCTION}

Fill dams have, until recently, been designed by specification-based design: stipulating the dam body materials, structural calculation method, and execution method in detail in design standards etc. Design based on the concept of specification-based design method to deal with large earthquake ground motion which rarely occurs, that produced by the 1995 Hyogo-ken Nanbu Earthquake for example, includes irrational aspects. So since the Hyogo-ken Nanbu Earthquake, the concept of performance-based design which treats the performance of a structure to be the only requirement has been introduced, and as a way to shift the design of earth structures such as levee embankments and road embankment etc. from the conventional specification-based design to performance-based design which accords with required performance, the concept of performance-based design has now been incorporated into Japan's Design Standards for Railway Structures (2004). And as international seismic standards for geotechnical works, ISO23469 (2006) has been enacted, incorporating the concept of performance-based design. Because a fill dam is characteristically a water storage structure, the performance a fill dam must ensure that water stored by the dam does not overflow the dam body nor breach the dam body during an earthquake, causing damage downstream of the dam. Thus, settlement at the crest of a fill dam during an earthquake must not be exceeding the performance criterion. To make this possible it is essential to design the dam applying an analysis method which can accurately predict the settlement which will occur. In the paper of Tani (Tani et al., 2005), the following study was done by the concept of setting the performance criterion index as the settlement based on the relationship of the surplus height and the settlement of a fill dam body. The Public Works Research Institute (2007) announced a performance criterion incorporating a deformation verification method which treats settlement as the evaluation index. And recently, during the 2004 Niigata Chuetsu Earthquake, maximum acceleration of $558\left(\mathrm{~cm} / \mathrm{s}^{2}\right)$ was recorded in the foundation of the Kawanishi Dam and then in 2008 during the Iwate, Miyagi Inland Earthquake, maximum acceleration of $1,000\left(\mathrm{~cm} / \mathrm{s}^{2}\right)$ was recorded at the basement of the dam. It has now become important to verify safety against large earthquake ground motion at fill dams. This report describes the study of a fill dam, which requires a high level of seismic performance be-

i) National Institute for Rural Engineering, Japan (stani@affrc.go.jp).

ii) Takenaka Civil Engineering \& Construction Co. Ltd., Japan.

iii) Takenaka Corporation Co. Ltd., Japan.

The manuscript for this paper was received for review on January 9, 2008; approved on June 18, 2009.

Written discussions on this paper should be submitted before July 1, 2010 to the Japanese Geotechnical Society, 4-38-2, Sengoku, Bunkyo-ku, Tokyo 112-0011, Japan. Upon request the closing date may be extended one month. 
cause of its location conditions and functions. The study was performed with an existing fill dam as a typical model and applying the concepts of ISO23469 concerning way of setting the seismic wave, the procedure and method of evaluating seismic performance, and evaluation method to this model in order to focus on (1) setting the performance criteria, (2) evaluating the safety of the dam in its present condition during an earthquake and (3) studying its safety during an earthquake hypothesizing a specific cross-section in the case of seismic reinforcement. It also included a study of a reinforcement method which satisfies the performance criterion.

\section{PERFORMANCE CRITERIA}

The relationship between maintaining functions and degree of damage differs according to structure, so it is difficult to determine this uniformly. The safety of earth structures is generally evaluated by the ultimate analysis method, but in a case considering level 2 earthquake ground motion, it is impossible to explain the degree of risk that the safety factor, of an embankment for example, will fall below 1.0 resulting in failure of the embankment, or whether it is safe. Even if the safety factor has fallen lower than 1.0, it will not necessarily fail immediately, and therefore it is necessary to clarify to what degree it is at risk or is safe according to the quantity of displacement. In the case of a fill dam, to keep its function as a water storage structure, the settlement related to the reservoir water level is particularly important. To learn the quantity of displacement in order to perform this clarification, it is necessary to perform detailed analysis, viz., FEM analysis. Even assuming that the 'accurate residual displacement' can be analyzed, it is next necessary to determine the performance criterion, "to what degree the residual displacement can be allowed". The performance criterion is determined in combination with the earthquake ground motion. Possible performance criterion for a fill dam is described below.

(1) Damage shall not occur under level 1 earthquake ground motion.

(2) Breaching shall not occur under level 2 earthquake ground motion.

(3) Damage shall be limited to the extent that does not obstruct control of the stored water under level 2 earthquake ground motion (the water level can be reduced before a breach occurs).

(4) It shall be possible to use the dam as before by performing only minor repair work after level 2 earthquake ground motion (to maintain total reservoir functions).

The significance of the concepts, (2) and (3) is almost identical. Requirement (4) applies when a fill dam has an extremely important role in society (cases where the dam plays an extremely important role in preventing disasters downstream from its location, or where its failure to supply water for irrigation would have extremely great repercussions), and in the past, this level of seismic performance was almost never demanded. And even when the settlement is small, leakage may rise and hence piping and others could cause breaching, but because it is assumed that this is not easily evaluated analytically, at this time, a quantitative "performance criterion" item cannot be incorporated. Thus, realistically, setting the allowed maximum values of the settlement or deformation and performing design that satisfies these values is performance-based design accounting for seismic performance of a fill dam.

In a case of damage during the Niigata Chuetsu Earthquake (Kawanishi Dam), the maximum acceleration of earthquake ground motion was $558\left(\mathrm{~cm} / \mathrm{s}^{2}\right)$ at the foot of the dam, which can be described as a level 2 earthquake ground motion in contrast to earthquake ground motion recorded in the past. The deformation of the crest was between 20 and $40 \mathrm{~cm}$. The settlement was within the allowed range, but small scale surface slippage occurred on the left bank upstream slope, and work to repair it prevented the supply of irrigation water for one year, making this a case where the damage had a severe impact (Tani et al., 2005). To achieve (4) "It shall be possible to use the dam as before by performing only minor repair work after level 2 earthquake ground motion (to maintain total reservoir functions)" as the performance criterion for cases such as this, cases where the required target criteria are overall deformation and relatively light slippage failure are considered, in spite that the performance criterion is normally either (2) or (3).

These performance criteria can be checked by settlement of the crest as an index of the performance required of a water storage structure. Considered from the perspective of the functions of the dam, the settlement must be kept within a range that permits the maintenance of its water storage functions under level 2 earthquake ground motion. Seismic design that stipulates performance criteria for a fill dam is done by determining the earthquake ground motion to be used for the design and performing design so that the deformation or the damage that it would cause will not harm the predetermined functions.

If, in this case, it is assumed that the function of a fill dam is to maintain its ability to continue to store water safely, the minimum requirements are that the crest elevation after an earthquake is not lower than the reservoir water level, or in other words, that the settlement is within the allowable height of the embankment. The stored water must not overflow the dam body in order to maintain the minimum required water storage function, and it may be limited to the range of the allowed height of the dam body plus the height of the waves caused by the earthquake. The allowable height equation is set by dam design standards. The numerical value obtained by this equation is the allowed quantity of settlement, and regardless of the dam height, a minimum of $1.0 \mathrm{~m}$ is ensured. But it has been reported that if large deformation occurs (Seed, 1979), cracking, sliding, piping or other damage and alteration may occur at various locations.

According to the Public Works Research Institute (Technical Note, 2005), for the cases that slippage is not 
predicted on a downstream slope, there must be no possibility of piping failure force being generated. In fact that there have been almost no reports of past damage cases exceeding $0.5 \mathrm{~m}$ among past earthquake damage to fill dams, excluding cases of foundation ground liquefaction etc. So considering these facts, the Technical Note sets the performance criterion approximately as 1.0 $m$ regardless of the dam height, as a judgment on the safe side.

This can be considered as the index for the performance criteria (2). And if errors of analysis etc. are considered to set the criterion value on the safe side, settlement of about $50 \mathrm{~cm}, 50 \%$ of approximately $1.0 \mathrm{~m}$ is considered to be the allowed settlement criterion. The error due to soil models and analysis methods cause the analysis result to differ. According to a reference, JGS (2007), comparing an experimental result with a prediction result by dynamic analysis, the calculated settlement of embankment ranges from around $0.5 \mathrm{~m}$ to $2.0 \mathrm{~m}$ when actual settlement of embankment at the crest is $1.0 \mathrm{~m}$. In the realm assumed to be safe, settlement of embankment, which can actually occur, is rationally thought at the current moment to become twice the analytic value.

In the case of slip analysis, the criterion index is a safety factor and its value was assumed to be a slip safety factor of 1.20 or more by the most of seismic performance regulations of civil structures.

\section{EVALUATING EARTHQUAKE ACTION}

In the case studied, seismic diagnosis was performed as specified by ISO23469, stipulated as an international seis-

Table 1. ISO23469 compliance check list

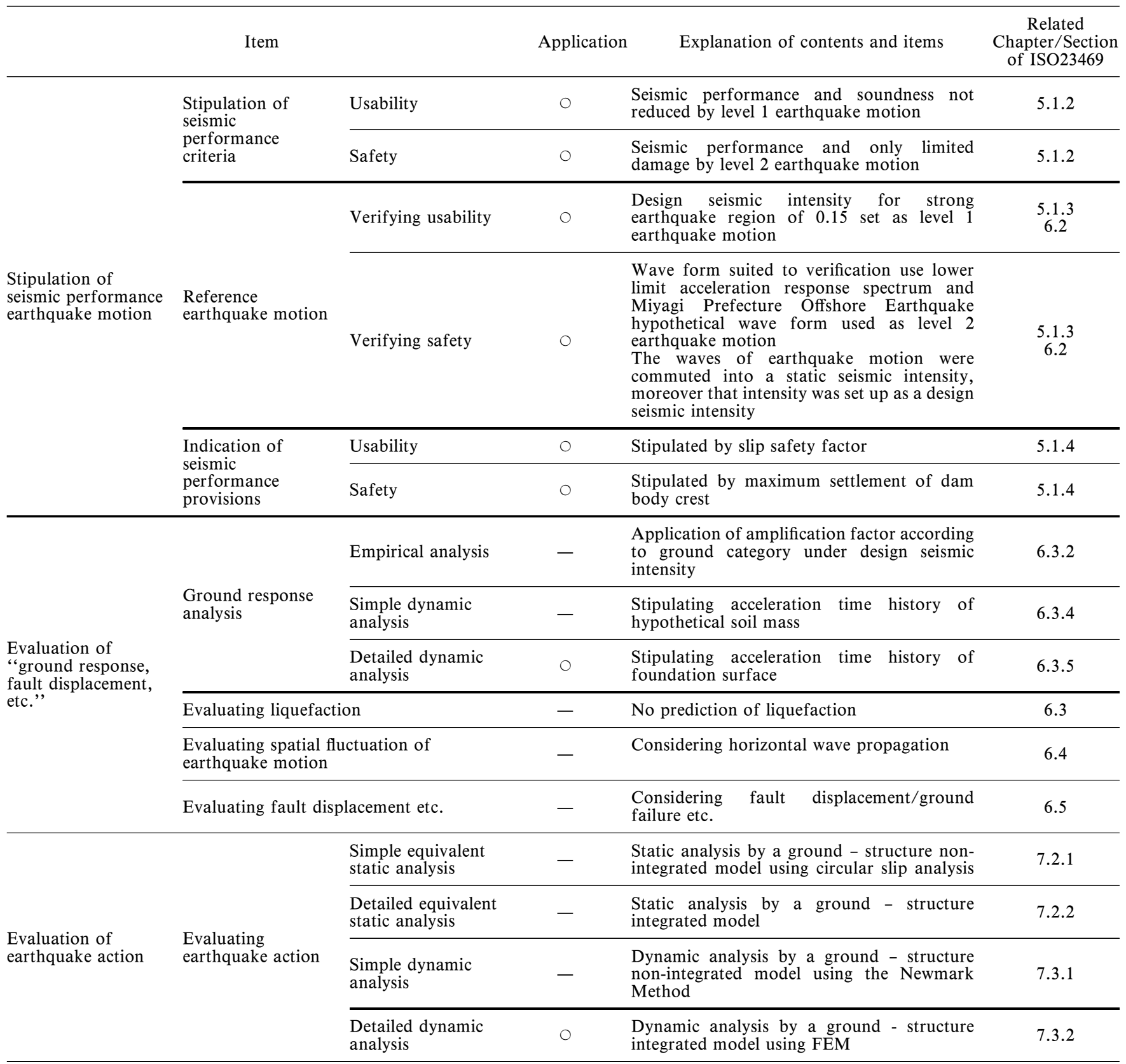


mic standard. Table 1 checked the conformity of the case studied with ISO23469 for each item. The explanation of the content and item of Table 1 was configured by the authors based on the guideline of ISO23469. Moreover, in this paper the performance target and the checking criterion of safety were specifically set up and the safety evaluation and the effect of the countermeasure of antiseismic reinforcement were considered. In Table 1, the numbers are the corresponding to ISO23469 chapter numbers, $\bigcirc$ indicates location compliance in the report and - indicates items which were not considered. It shows that a specific value has not been indicated by the standard, so these values are defined by this analysis. This report used a design earthquake force stipulated by the dam standard for level 1 earthquake ground motion (2003). For level 2, it is earthquake ground motion with the highest level strength assumed to occur from the present time into the future at the dam site, as defined by the dam seismic standard (2005). Specification of earthquake ground motion is explained below. Provisions for usability of the performance criterion during and after an earthquake were assumed to be seismic performance under level 1 earthquake ground motion. The lateral seismic intensity $k_{\mathrm{h}}=0.15$ in a strong earthquake region, which is generally used for the seismic design of fill dams in Japan, was the reference earthquake ground motion of level 1 earthquake ground motion. The analysis method was slip surface analysis based on circular slip. The lateral seismic intensity $k_{\mathrm{h}}=0.35$ for level 2 earthquake ground motion on ground surface, which is used to verify seismic performance according to the static verification method stipu-

Table 2. Verification use lower limit response spectrum (damping con$\operatorname{stant}=\mathbf{5} \%$ )

\begin{tabular}{cl}
\hline $\begin{array}{c}\text { Range of the natural } \\
\text { period } T(\mathrm{sec})\end{array}$ & Acceleration response spectra $S_{\mathrm{A}}(\mathrm{gal})$ \\
\hline $0.02 \leqq T<0.1$ & $S_{\mathrm{A}}=400 / 0.08 \times(T-0.02)+300$ \\
$0.1 \leqq T \leqq 0.7$ & $S_{\mathrm{A}}=700$ \\
$0.7<T \leqq 4$ & $S_{\mathrm{A}}=700 \times(T / 0.7)^{-1.642}$ \\
\hline
\end{tabular}

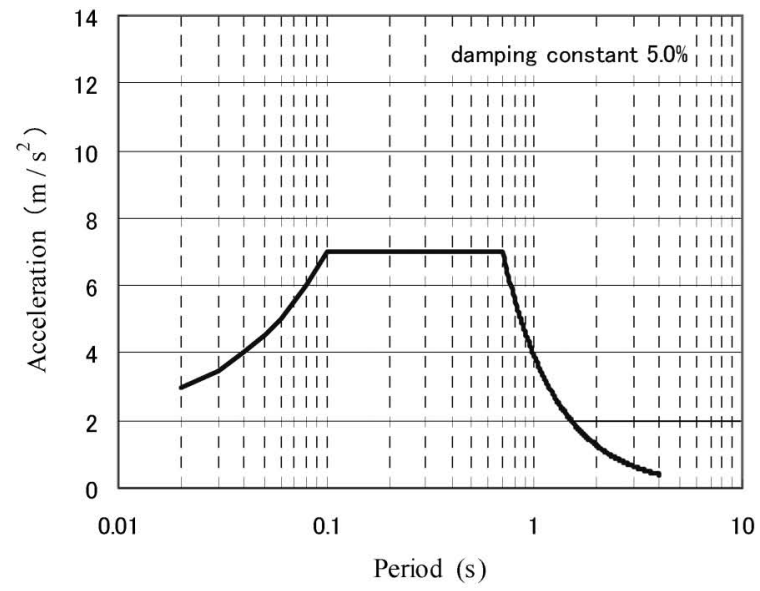

lated in 'Specifications for highway bridges (PART V Seismic design, 2004), was applied.

The following two kinds of seismic wave were used as the reference earthquake ground motion considered as level 2 earthquake ground motion.

(1) A seismic wave prepared using the Hachinohe wave NS component from the Tokachioki Earthquake of 1968 as the observed wave, assuming that a seismic wave conforming to the verification use of lower limit acceleration response spectrum shown in Fig. 1 and Table 2. The wave prepared considering the phase characteristics of observed waves (called the "simulated Hachinohe Wave"); and the seismic wave simulation prepared using the upstream-downstream component observed in ground on the left bank of the Kawanishi Dam (A central core type fill dam with height of $43 \mathrm{~m}$ ) in Tokamachi City during the Chuetsu Earthquake of 2004 (called the "Kawanishi Wave").

(2) Seismic wave at the hypothetical site in Sendai City (North latitude $38.4013^{\circ}$, East longitude $141.2117^{\circ}$ ) of the seismic wave prepared by the statistical Green Function Method using the fault model of the 1978 Miyagi Offshore Earthquake (called the simulated "Miyagi Wave") shown in Fig. 2. Figure 3 shows the acceleration time histories and acceleration response spectra of the above three waves. The level 2 earthquake ground motion was input at the depth of the ground surface for seismic foundation design.

\section{ANALYSIS METHOD}

Soil Constants Used for the Model Section and Analysis The section of the model dam set with reference to an existing central core type fill dam is shown in Fig. 4. The section of the model dam was set with dam height of 36.5 $\mathrm{m}$ (depth at the dam body crest of $36.5 \mathrm{~m}$ ), crest width of $7.0 \mathrm{~m}$, and gradient of 1.0:3.0 on the upstream side and 1.0:2.3 on the downstream side. The water level was the full reservoir level ( $4.0 \mathrm{~m}$ below the crest), and below the dam body, a foundation with $N$ value of 20 was set with thickness of $12.0 \mathrm{~m}$, while the ground below the founda-

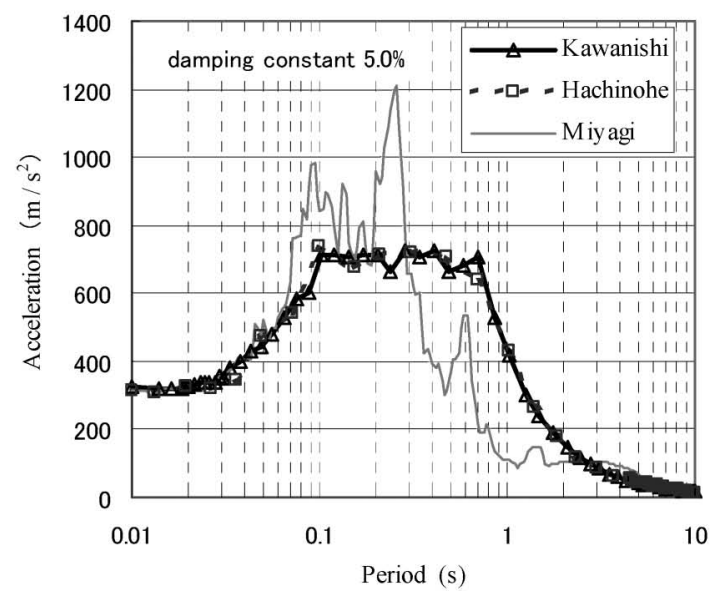

Fig. 1. Verification use lower limit acceleration response spectrum 


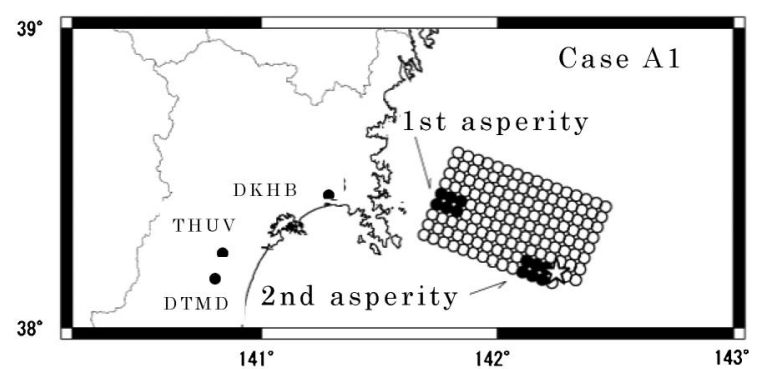

Assumed fault model based on data from the 1978 Miyagi-kenOki Earthquake (Case A1)

- : asperity

is : Rupture initiation point

Sites where deserved wave form of 1978 Miyagi-ken-Oki Earthquake were recorded

DKHB : Kaihokubashi

THUV : Tohoku University

DTMD : Tarumizu Dam

Fig. 2. Fault model

- Simulated earthquake Kawanishi

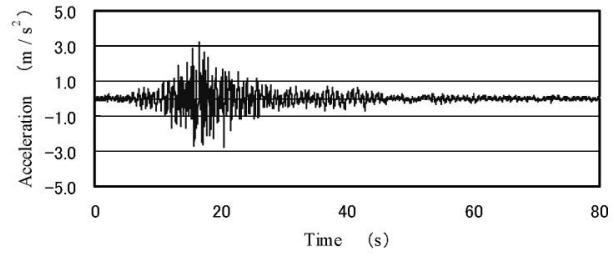

- Simulated earthquake Hachinohe

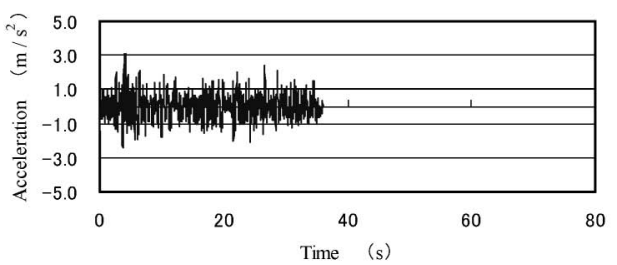

- Simulated earthquake Miyagi

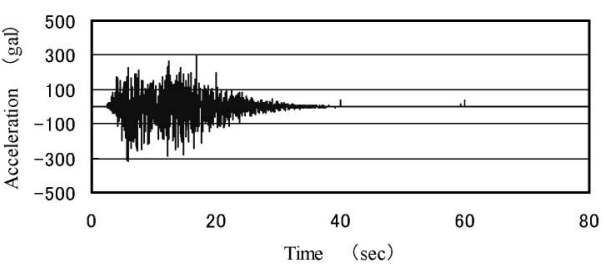

Fig. 3. Acceleration time history and acceleration response spectra

tion was set as a foundation with shear elastic wave velocity $V_{\mathrm{s}}=1,500 \mathrm{~m} / \mathrm{s}$.

Figure 5 shows three sections used to study seismic reinforcement measures. The details of the seismically reinforced sections are shown in Table 3: in reinforcement section (1), counterweight fill crest width of $5.0 \mathrm{~m}$, height of $34.5 \mathrm{~m}$, upstream slope gradient of 1.0:4.0 and downstream slope gradient of 1.0:3.3, and in reinforcement section (2), counterweight fill crest width of $5.0 \mathrm{~m}$, height

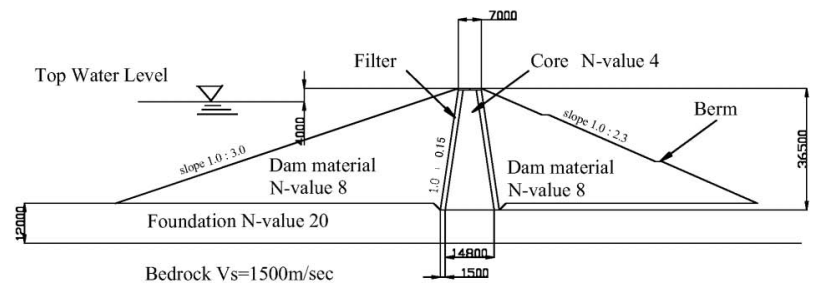

Fig. 4. Section of the model dam

- Reinforcement Case(1)

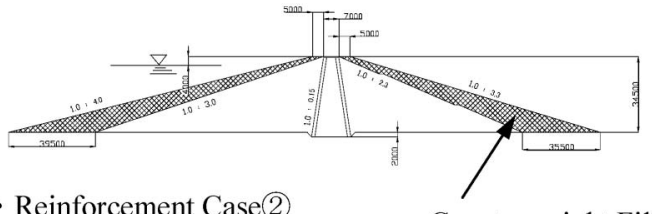

- Reinforcement Case 2

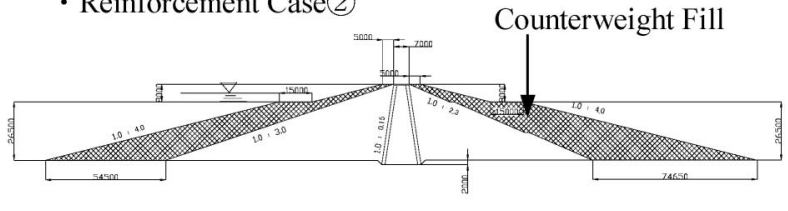

- Reinforcement Case(3)

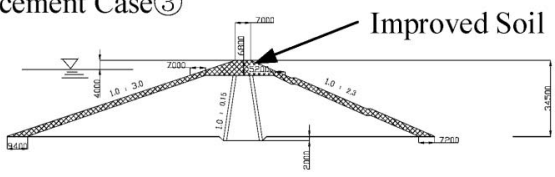

Fig. 5. Seismic reinforcement sections

of $34.5 \mathrm{~m}$, upstream and downstream slope gradients of 1.0:4.0, and midway, berms with width of $15 \mathrm{~m}$. In reinforcement section (3), the inside of the existing dam body was replaced with improved soil. The material used as a counterweight fills in reinforcement section (1) and reinforcement section (2) were the same material as the dam body. The improved soil in reinforcement section (3) was low strength improved soil.

Figure 6 shows the model dam analysis mesh. The meshes on the dam body were divided so that the mesh lines appear parallel to the slope surface. The initial stress needed during FEM dynamic analysis was obtained by self-weight analysis performed using the Mohr-Coulomb model. Boundary conditions during self-weight analysis were fixed bottom surface and vertical rollers on the sides. During dynamic analysis, as shown in Fig. 6, free ground was formed on the sides, and as boundary conditions, a viscous boundary formed on the bottom surface, and on the sides, a viscous boundary between it and the free ground were used.

Table 4 shows the ground constants used for the analysis. The density was set with reference to the density of existing dams. $V_{\text {s }}$ was calculated based on the $N$ value and the $N$ values of the dam body and core were set with reference to boring data from an existing dam. The internal friction angle was, like the density, set with reference to data from an existing dam. The cohesion value has a big impact on analysis results, but for this test, an empirical value was used. Shear stiffness was set with reference 
Table 3. Specifications of reinforcement sections

\begin{tabular}{cccc}
\hline & Reinforcement section (1) & Reinforcement section (2) & Reinforcement section (3) \\
\hline Reinforcing method & Counterweight fill & Counterweight fill & Improved soil \\
\hline Crest width after reinforcement & $17 \mathrm{~m}$ & $17 \mathrm{~m}$ & $7 \mathrm{~m}$ \\
\hline Upstream side slope gradient & $1.0: 4.0$ & $1.0: 4.0$ & $1.0: 3.3$ \\
\hline Downstream side slope gradient & $1.0: 3.3$ & $1.0: 4.0$ & $1.0: 2.3$ \\
\hline Reinforced location & Outside of existing part & Outside of existing part & Inside of existing part \\
\hline
\end{tabular}
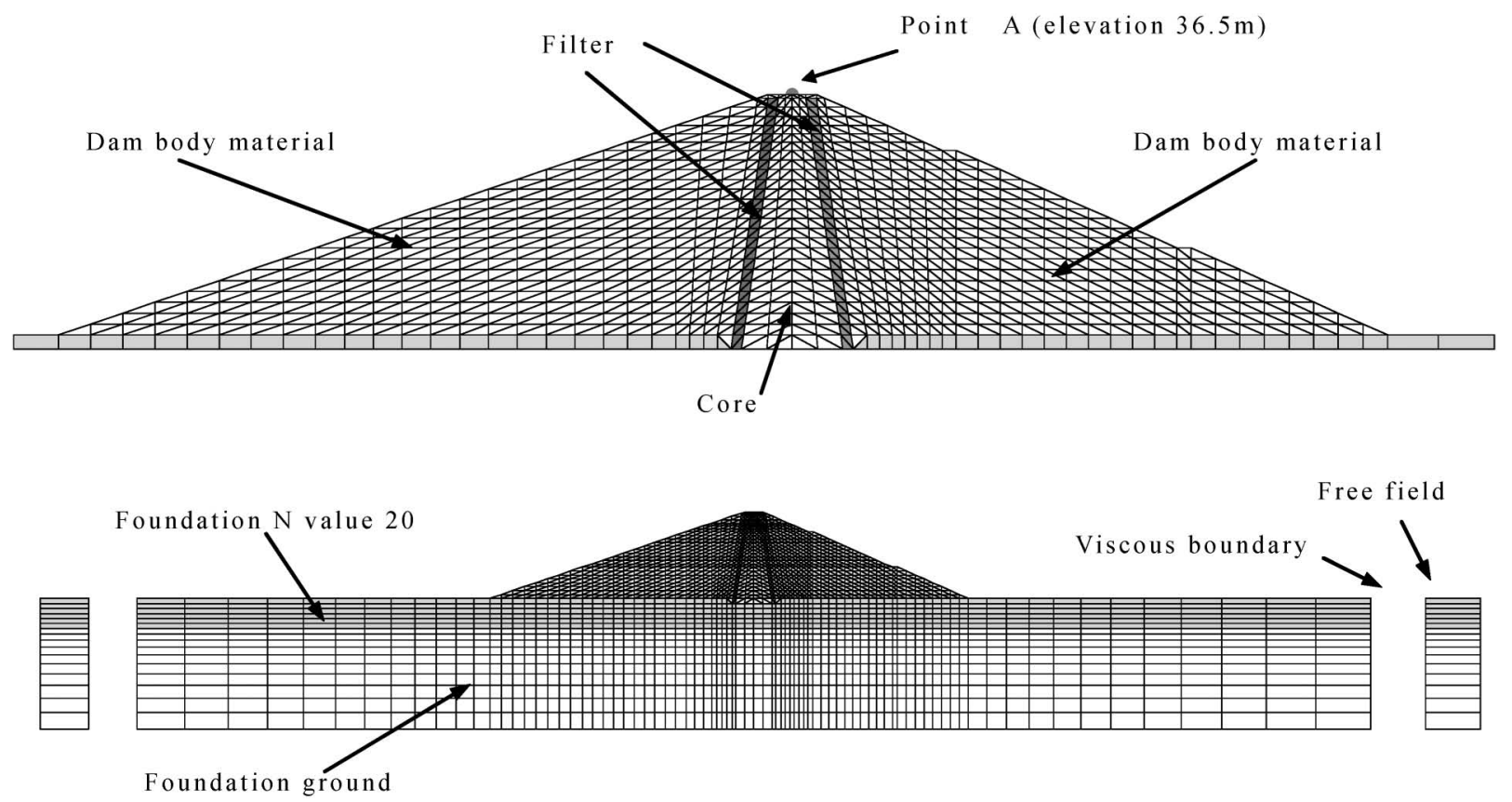

Fig. 6. Analysis mesh

Table 4. Ground constants used for the analysis

\begin{tabular}{lccccccc}
\hline \multicolumn{1}{c}{ Material category } & $N$ value & $V_{\mathrm{s}}(\mathrm{m} / \mathrm{s})$ & $\begin{array}{c}\text { Saturation } \\
\text { density }\left(\mathrm{t} / \mathrm{m}^{3}\right)\end{array}$ & $\begin{array}{c}\text { Internal friction } \\
\text { angle } \phi\left({ }^{\circ}\right)\end{array}$ & $\begin{array}{c}\text { Cohesiveness } \\
C\left(\mathrm{kN} / \mathrm{m}^{2}\right)\end{array}$ & $\begin{array}{c}\text { Shear stiffness } \\
\left(\sigma_{\mathrm{c}}=100 \mathrm{kN} / \mathrm{m}^{2}\right)\end{array}$ & $\begin{array}{c}\text { Young's modulus } \\
\left(\mathrm{kN} / \mathrm{m}^{2}\right)\end{array}$ \\
\hline Dam body material & 8 & 170 & 1.86 & 32 & 5 & 53754 & - \\
\hline Core & 4 & 133 & 1.74 & 28 & 10 & 30778 & - \\
\hline Filter & - & - & 2.17 & 40 & 0.1 & 203200 & - \\
\hline Foundation & 20 & 237 & 2.1 & 32.3 & 0.1 & 117955 & - \\
\hline Foundation ground & - & 1500 & 2.2 & - & - & 4950000 & - \\
\hline Improved soil & - & - & 1.86 & 10 & 100 & - & 100000 \\
\hline
\end{tabular}

Poisson's ratio is 0.41 above seepage line, and 0.49 below seepage line.

to test data from existing dams, and the dam body material, core, and filter adopted were dependent on confining pressure proportional to the square root of the confining pressure. The Young's modulus of the improved soil was set at 500 times the unconfined compressive strength $q_{\mathrm{u}}$ of the improved soil. Poisson's ratio was set at 0.41 above the seepage line and at 0.49 below the seepage line based on records of seismic prospecting performed at an existing dam during dynamic analysis and assuming that the static coefficient of earth pressure during self-weight analysis ranged from 0.5 to 0.33 .

Rayleigh damping was used for damping of dynamic analysis. The parameters of Rayleigh damping were set as damping of $2.5 \%$ as the criterion for lateral primary and secondary natural periods of 0.704 seconds and $0.363 \mathrm{sec}-$ onds. The constitutive equation of soil used was the Mohr-Coulomb model. With the Mohr-Coulomb model, the non-associated flow rule is used where the plastic 
Table 5. Table of slip safety factors during earthquakes

\begin{tabular}{|c|c|c|c|c|}
\hline \multirow[b]{2}{*}{ Reinforcing material } & \multicolumn{2}{|c|}{$\begin{array}{l}\text { Safety factor during earthquake } \\
\qquad\left(k_{\mathrm{h}}=0.15\right)\end{array}$} & \multicolumn{2}{|c|}{$\begin{array}{l}\text { Safety factor during earthquake } \\
\qquad\left(k_{\mathrm{h}}=0.35\right)\end{array}$} \\
\hline & Dam body material & Improved soil & Dam body material & Improved soil \\
\hline No countermeasure & 1.357 & - & 0.889 & - \\
\hline Reinforcement section (1) & 1.624 & - & 1.018 & - \\
\hline Reinforcement section (2) & 1.634 & - & 1.018 & - \\
\hline Reinforcement section (3) & - & 1.438 & - & 0.954 \\
\hline
\end{tabular}

volume strain is considered to be zero, so volume change such as shaking down is not modelled by this analysis. And because the Mohr-Coulomb model is a yield in-plane elastic model until hysteresis characteristics reach the yield surface, it displays elastic behaviour. After they reach the yield surface, it displays totally plastic behaviour. The non-linear numerical analysis algorithm was the initial stiffness method. Time integration was done using the Newmark $\beta$ method $(\gamma=0.5, \theta=0.25)$ : and the analysis performed at intervals of 0.001 second.

\section{Analysis Results-Slip Analysis Results}

Earthquake action has been evaluated by studies using two analysis methods: (1) circular slip surface analysis and (2) FEM dynamic analysis. The lateral seismic intensity $k_{\mathrm{h}}$ used for circular slip surface analysis was calculated using the standard seismic intensity in a strong earthquake district $K_{\mathrm{h}}=0.15$. As further reference, the lateral seismic intensity of level 2 earthquake ground motion on ground surface, which is used to verify seismic performance-based on the static verification method stipulated in 'Specifications for highway bridges (PART V Seismic design) (2004), was applied. If the categorization in the same standard is used, the ground categories of the sections shown in Fig. 4 are divided into 2 ground categories, and $k_{\mathrm{h}}=0.35$. The lateral seismic intensity was input uniformly to the dam body.

Table 5 shows a list of safety factors during an earthquake. Figure 7 shows slip sections during an earthquake. Slip surfaces are shown on the upstream side for all sections. Although the slope gradients are steeper on the downstream sides than on the upstream sides, the slip surface appears on the upstream sides because the shear strength on the upstream sides is lower than it is on the downstream sides, because of the decline of the effective stress as a result of the buoyancy in parts below the water level. In the $K_{\mathrm{h}}=0.15$ case, the slip safety factor $S_{\mathrm{f}}>1.20$. It is hypothesized that in a case where $K_{\mathrm{h}}=0.35$ under present conditions, $S_{\mathrm{f}}=0.889<1.0$ and slipping occurs.

The safety factors of reinforced sections are all higher than the safety factors of sections of a model dam without countermeasures. Among the reinforcement sections, the safety factor of reinforcement section (3) is the lowest, while the safety factors of reinforcement section (1) and reinforcement section (2) with reduced slope gradients are high, and the effects of berms of reinforcement section (2) appear. While the slip surface of the
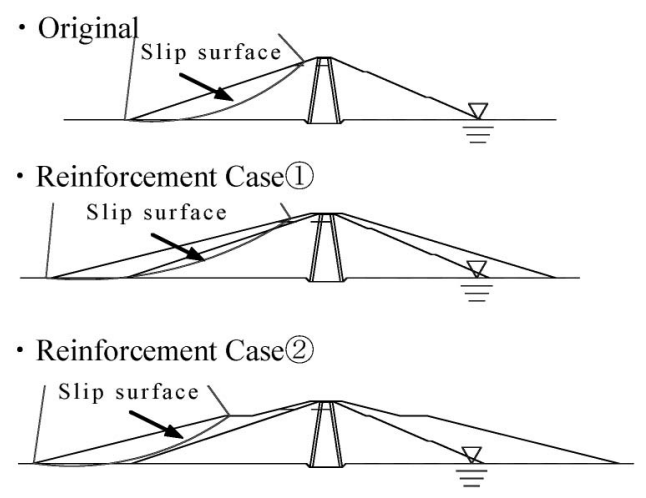

- Reinforcement Case(3)

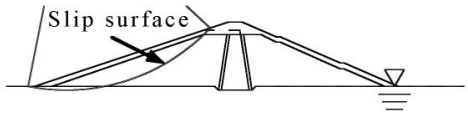

Fig. 7. Slip surface during an earthquake

model dam section forms a large arc passing through the dam body crest from the toe of the upstream slope, the slip surface of reinforcement section (3) is an arc that passes through the middle of the upstream side slope from the toe of the upstream side slope, and the arc does not pass through the crest presumably because the effects of the cohesiveness of the improved soil appears. In reinforcement section (3), the part where the slip surface passed through the improved soil was small, so the slope gradient was gentle and the seismic reinforcement effects were lower than the strength provided by the counterweight fill of reinforcement section (1) and reinforcement section (2). The circular slip surface analysis shows that the slope gradient is gentle and the reinforcement of the counterweight fill is effective. The same tendency is seen in a $K_{\mathrm{h}}=0.35$ case.

\section{Results of FEM Dynamic Analysis}

Table 6 shows the maximum settlement at the dam body crest as obtained by FEM dynamic analysis. The maximum settlement of the dam body crest appeared near the shoulder of the downstream slope in all sections. The seismic reinforcement effects are highest in reinforcement section (3) where the inside of the existing dam body was replaced with improved soil, and the maximum settlement fell to a little more than $1 / 3$ of that in the section of the model dam without countermeasures. A compari- 
son of reinforcement section (1) and reinforcement section (2) that were seismically reinforced with counterweight fill shows that the seismic reinforcing effects were higher in reinforcement section (2) where the slope gradient on the downstream side was gentler than reinforcement section (1), berms with width of $15 \mathrm{~m}$ were constructed, and the section of the counterweight fill was large. Also it is known that because the settlement of the simulated Kawanishi wave is greater than that of the simulated Hachinohe wave although their acceleration response spectra are identical, the phase difference is revealed in the results of the analysis. The settlement in a case using the simulated Miyagi wave is smaller than it is when other seismic waves were used because the power near the horizontal primary natural period of $0.704 \mathrm{sec}-$ onds is smaller than that of the simulated Hachinohe wave and the simulated Kawanishi wave. Because the natural period of this dam and the natural period of the simulated Miyagi wave deviate, it is assumed that this is the main reason that the settlement is smaller than when another earthquake is used. In addition, it is reportedly an impact of the soil constants and attenuation constant

Table 6. Maximum settlement of dam body crest by FEM dynamic analysis

\begin{tabular}{|c|c|c|c|}
\hline & \multicolumn{3}{|c|}{ Maximum settlement of dam body crest (m) } \\
\hline Earthquake wave & $\begin{array}{l}\text { Kawanishi } \\
\text { Wave }\end{array}$ & $\begin{array}{c}\text { Hachinohe } \\
\text { Wave }\end{array}$ & $\begin{array}{l}\text { Miyagi } \\
\text { Wave }\end{array}$ \\
\hline No countermeasure & 0.676 & 0.606 & 0.268 \\
\hline Reinforcement section (1) & 0.507 & 0.433 & 0.146 \\
\hline Reinforcement section (2) & 0.384 & 0.326 & 0.073 \\
\hline Reinforcement section (3) & 0.244 & 0.242 & 0.102 \\
\hline
\end{tabular}

(Tani et al., 2005).

Figures 8 and 9 show deformation and the $\gamma_{\max }$ contour at the final analysis step when using the simulated Kawanishi wave as input earthquake ground motion. The section of a model dam without countermeasures and of all reinforcement sections is severe on the upstream side, and the peak of $\gamma_{\max }$ also appears on the upstream side. And deformation considered to be caused by shear occurs in deep parts of the dam body. While in reinforcement section (1) and reinforcement section (2), the value of $\gamma_{\max }$ is high even near the crest, in reinforcement section (3) where the seismic reinforcing effects were found to be highest by FEM analysis, the value of $\gamma_{\max }$ near the crest is small because under the effects of cohesiveness of the improved soil, near the crest where the depth is shallow and confining pressure is low, it is possible to count on shear strength. Consequently, it is assumed that it would be effective to perform reinforcement with materials that can be counted on to be cohesive near the dam body crest, but in seismic reinforcement section (3), the maximum shear strain was highest near the boundary of the improved soil with the dam body material on the upstream side. This is a result of the fact that the response differed near the boundary because of differences between the stiffness of the improved soil and the dam body material, and the dam design must be performed paying close attention to this point.

Figure 10 shows the relationship of the maximum settlement of each section crest obtained by FEM analysis with the slip safety factor during an earthquake obtained by circular slip surface analysis. No correlation can be found between slip safety factor and the maximum residual settlement at the dam body crest obtained by FEM analysis. FEM analysis based settlements for reinforce-

- Original

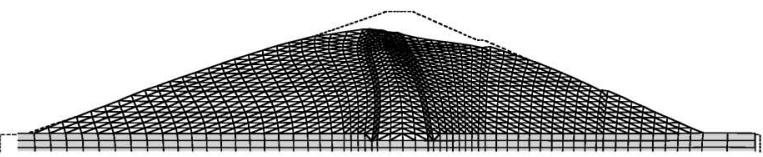

- Reinforcement Case (1)

Broken line : Initial deformation

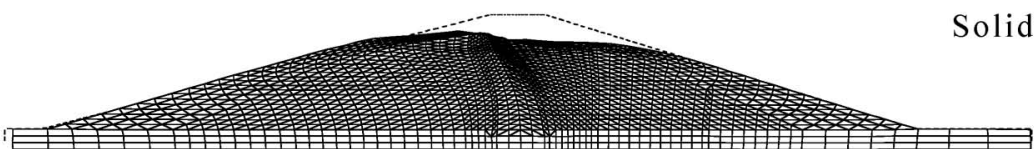

Solid line : Residual deformation

- Reinforcement Case(2)

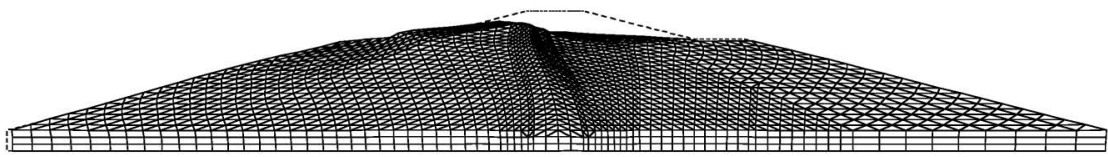

- Reinforcement Case(3)

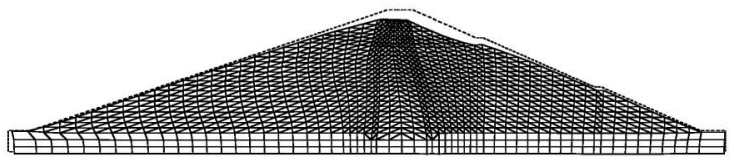

Fig. 8. Residual deformation diagram (Unit m) (Input earthquake motion: Kawanishi wave) 
- Original

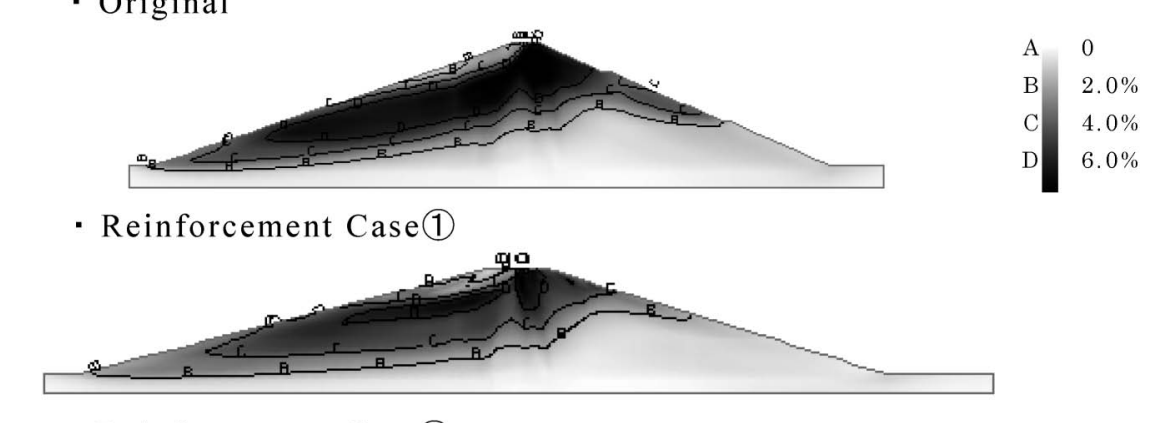

- Reinforcement Case(2)

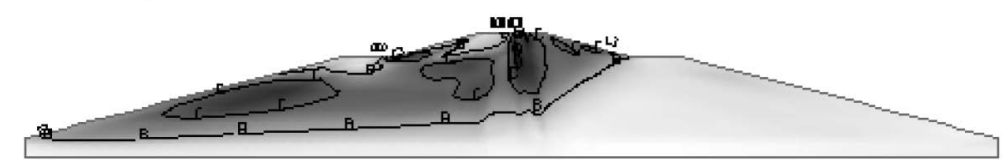

- Reinforcement Case(3)

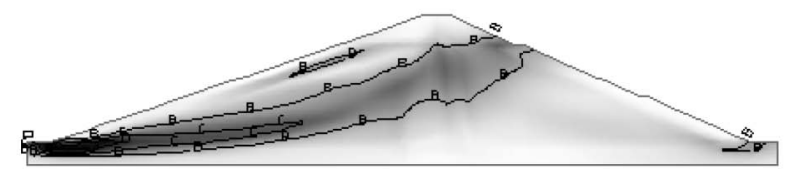

Fig. 9. $\gamma_{\max }$ contour diagram at final step of analysis (Input earthquake motion: Kawanishi wave)

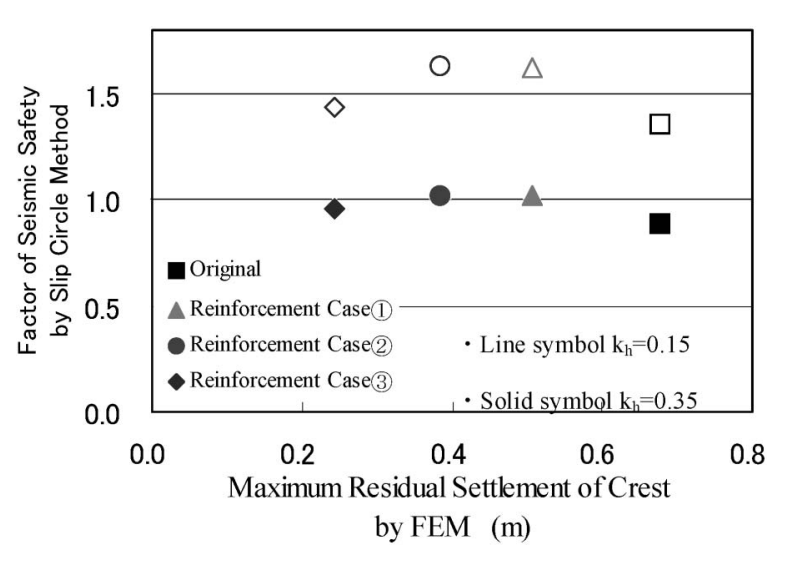

Fig. 10. FEM Analysis residual settlement - Slip safety factor relationship

ment sections (1) and (2) differ despite their identical slip safety factors, because, while slip surfaces with minimum safety factors in reinforcement sections (1) and (2) do not pass through the entire dam body as shown in Fig. 7, in the deformation chart, Fig. 8, obtained by FEM analysis, shear deformation occurs deep in the body and the slip surface analysis shows no overall dam body shear deformation, so that even with identical slip safety factors, the settlements obtained by FEM analysis differ.

The slip safety factor of reinforcement section (3) is smallest among the reinforcement sections, but because the slip surface with the minimum safety factor does not pass through the dam body crest, in case where the seismic performance is evaluated according to the settlement of the dam body crest, it is not necessarily true that the slip safety factor is lower than that of other reinforce- ment sections. FEM analysis considers the effects of shear deformation of the entire dam body that cannot be represented by slip surface analysis and the occurrence of displacement caused by localized concentration of strain near the dam body crest, but because it is analysis of a continuous body, it cannot clearly show the slip surface. In addition to that, the evaluations of seismic reinforcement effects vary because the failure modes considered by FEM analysis and by slip surface analysis differ in this way.

Figure 11 shows the time histories of the horizontal response acceleration and the vertical displacement in the centre of the dam body crest when the simulated Kawanishi wave is used as the input earthquake ground motion in the section of the model dam. From approximately 10 seconds when the main motion begins until approximately 45 seconds when it ends, the vertical displacement increased continuously. Figure 12 shows the depth direction distribution of the maximum values of the horizontal response acceleration, maximum shear strain $\gamma_{\max }$, and vertical displacement at the centre of the dam body in each section when using the simulated Kawanishi wave as the input earthquake ground motion. Near the crest, the horizontal response acceleration on the section of the model dam without countermeasures is smaller than it is in the reinforcement section, because the acceleration is not transmitted easily as a consequence of the rise of the quantity of strain and plasticization of deep parts of the dam body. Vertical displacement occurs also in deep parts of the dam body on all sections, but on reinforcement section (3), the quantity of vertical displacement near the crest that was replaced with improved soil is far smaller than it is in the other reinforced sections, revealing that the seismic reinforcing effect in reinforce- 

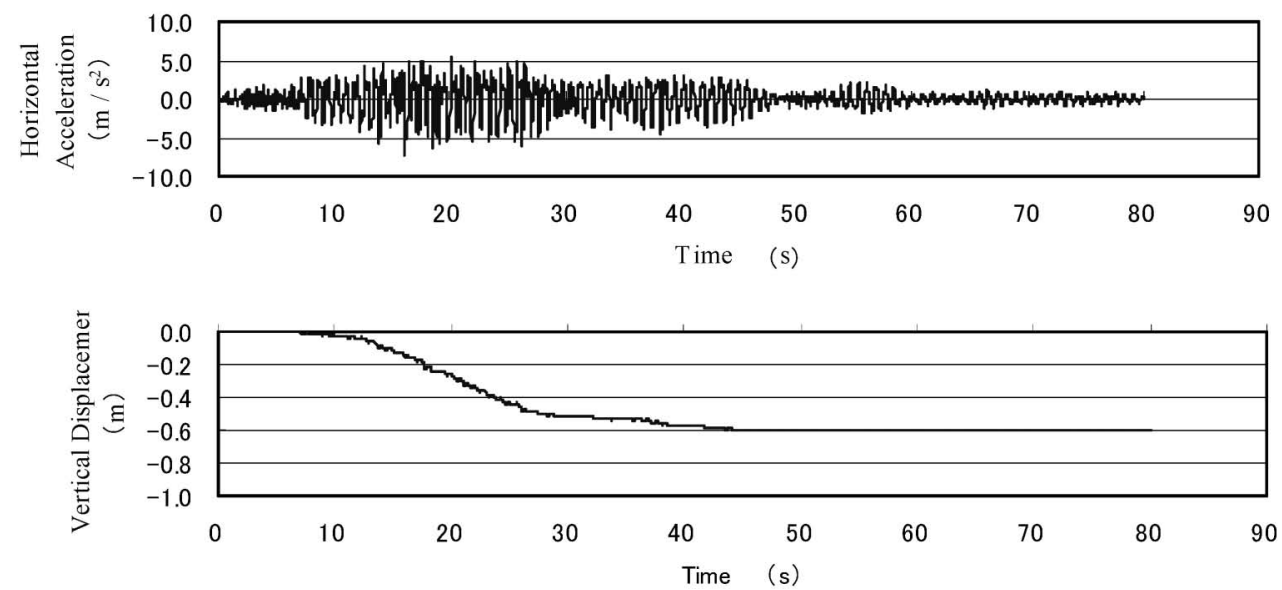

Fig. 11. Time history of response acceleration and vertical displacement at crest (Point A) of model dam (Input earthquake ground motion is Kawanishi wave)
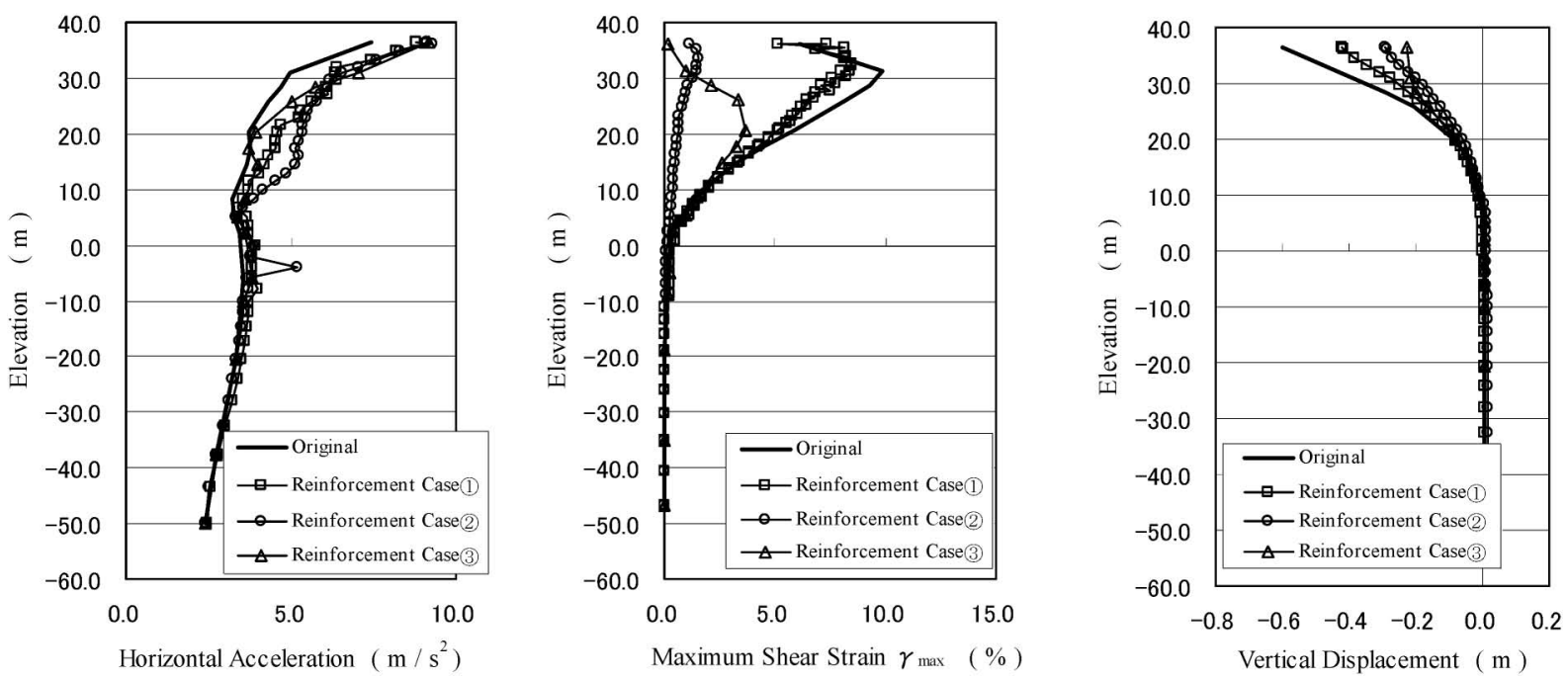

Fig. 12. Distribution of maximum values of horizontal acceleration, naximum shear strain and vertical displacement at center of dam body (Input earthquake notion: Kawanishi wave)

ment section (3) is highest because of the strong effects of the improved soil near the crest.

\section{CONCLUSIONS}

The study presented in this report was undertaken to establish the performance criteria required during an earthquake and to analytically study seismic diagnosis and seismic reinforcement measures of a model fill dam, considering the characteristic role of a fill dam as a water storage structure in line with ISO23469 which has been enacted as an international seismic standard. The following is a summary of the results obtained.

(1) Conventional slip analysis cannot calculate settlement. For a water storage structure such as a fill dam, it can evaluate residual settlement and it is appropriate for the evaluation of safety, but, because the settlement at a dam body crest obtained by FEM dynamic analysis varies according to the phase charac- teristics and acceleration response spectrum characteristics of seismic waves, it is an important challenge to decide how to set the reference earthquake ground motion. It is argued that because breaching of dams is scattered according to differences in the soil model, analysis method etc., it is difficult to apply these to design, but it is necessary to incorporate an analysis method such as FEM in performance-based design while maintaining safety, by considering the "safety factor type" coefficient in the analysis.

(2) As the performance criteria for a fill dam, it is presumed that a slip safety factor of 1.20 or more is necessary for level 1 earthquake ground motion, and that $1.0 \mathrm{~m}$ or less from the 'Free board' value is necessary for level 2 earthquake ground motion, but $0.5 \mathrm{~m}$ which is $50 \%$ of $1 \mathrm{~m}$ is proposed as a fill dam performance criterion considering the 'safety factor' type coefficient in the analysis.

(3) The effectiveness of seismic reinforcement performed 
by executing counterweight fill varies greatly according to the reinforcement method, so it is necessary to conduct a study to determine the optimum seismic reinforcement method including cost considerations.

(4) The crest settlement obtained by FEM analysis tends to be small if the slip safety factor obtained by circular slip analysis is small, but because the deformation mode and performance verification parameters differ, it is, at this time, difficult to quantitatively link the two results. If the study of more cases in the future establishes a relationship which permits the estimation of the approximate maximum settlement based on the slip safety factor, it may become possible to use the conventional slip safety factor as a "presumptive regulation", as a simple method for performing a primary verification for level 2 earthquake ground motion of multiple fill dams.

(5) Near the crest of a dam body where the shear strength is low because of its shallow depth and low constraining pressure, if cement improved soil which can be counted on to provide shear strength based on the cohesion $C$ is used; the seismic reinforcement effectiveness is enhanced.

(6) When improved soil has been used for seismic reinforcement, large strain tends to be generated near the boundary between the improved soil and the existing dam body material, and it is necessary to take reinforcement measures carefully.

This report describes a study of setting earthquake ground motion, setting performance criteria, and seismic resistance in order to verify the safety of a fill dam during an earthquake in accordance with the international seismic standard, ISO23469. Further this study of reinforce- ment methods presumably provides knowledge of use when performing performance-based design of actual fill dams.

\section{ACKNOWLEDGMENTS}

The Miyagi Wave data used was downloaded from the web site of the National Research Institute for Earth Science and Disaster Prevention (NIED) (http://www. j-shis.bousai.go.jp). The authors wish to express their gratitude to the NIED for allowing this use.

\section{REFERENCES}

1) ISO/TC98/SC3 (2005): ISO23469:2005 (Bases for design of structures -Seismic actions for designing geotechnical works).

2) Japan Road Association (2002): Specifications for Highway Bridges (Part V Seismic Design).

3) Japanese Geotechnical Society (2007): Symposium on the Performance-based Design for Soil Structures during Earthquakes and the Prediction of Deformation Volumes (in Japanese).

4) Japanese Society of Irrigation, Drainage and Reclamation Engineering (2003): Land Improvement Project Planning and Design Standards, Design (Dams) (in Japanese).

5) Public Works Research Institute (2005): Technical Note on Seismic Performance of Dams against Large Earthquakes (in Japanese).

6) Seed, H. B. (1979): Consideration of the earthquake-resistant design of earth rock fill dams, Geotechnique, 29(3), 215-263.

7) Tani, S. and Ariga, Y. (2005): Dam, Performance based Design in Earthquake, Japan Association for Earthquake Engineering, 51-81.

8) Tani, S., Tsukuni, S. and Shiomi, T. (2005): Estimation of residual deformation of earth -en dam subject to an earthquake, ICOLD Symposium in Madrid, 1-9.

9) Tani, S., Wakai, A. and Shiomi, S. (2005): Comparative study of earth dam by several FEM programs, Tsuchi-to-Kiso, 53(8), 19-22 (in Japanese). 